\title{
Factors Associated with Childhood Diarrhea in Rwanda: A Secondary Data Analysis of the Rwanda Demographic and Health Survey 2014-15
}

\author{
Malachie Tuyizere ${ }^{1 *}$, Theogene Nyandwi ${ }^{1}$, Amos Habimana ${ }^{1}$, Cyprien Munyanshongore ${ }^{1}$ \\ ${ }^{1}$ College of Medicine and Health Sciences, University of Rwanda
}

*Corresponding author: Malachie Tuyizere. College of Medicine and Health Sciences, University of Rwanda, Remera Campus, KG 11 Ave, 47, Kigali, Rwanda. Email: malaschie@gmail.com

\begin{abstract}
\section{Background}

Diarrheal diseases remain an important cause of morbidity among children, particularly in children under five years old, in low- and middle-income countries where it causes nearly 1.7 billion cases every year.

\section{Methods}

We used a quantitative cross-sectional design. This study aimed to explore the determinants of child diarrhea among under five-year children in Rwanda. A deep analysis of the 20142015 Rwanda Demographic and Health Survey (RDHS), with multivariate logistic regression, using stata13 was performed. The 2014-2015 Survey was the fifth standard national survey, implemented by the National Institute of Statistics of Rwanda (NISR) in a period of six months from November 2014 to April 2015.
\end{abstract}

\section{Results}

A sample of 2841 children under five years old were included. Chi-square test and logistic regression were performed. A significance level of 0.05 at $95 \%$ CI was considered. Child age and wealth index showed a strong association with diarrhea. Children in the age groups of 6-11, 12-23, 24-35 months were at higher risk of diarrhea than children aged 48-59 months, OR: 5.0 [3.1-8.2], P-value: 0.001; OR: 7.6, CI [4.7-12.2], P-value: 0.001; OR:3.8 [2.3-6.2], P-value: 0.001 respectively. Moreover, children from poorest and poorer families were twice more at risk of diarrhea than children from richest families. OR: 2, CI [1.3-2.9], P-value: 0.001.

\section{Conclusion}

The study concluded that low wealth index, and child age less than 35 months were important risks for under-five child diarrhea.

Rwanda J Med Health Sci 2019;2(3):230-234.

Key words: determinants, under five years children, diarrhea

\section{Introduction}

Diarrhea is the loss of three or more loss of liquid stools per day, or more frequently than is normal for the individual. $[1,2]$ Diarrhea is a high burden disease and accounts for nine percent of all deaths among children under five years old worldwide.[3] Diarrhea causes nearly 1.7 billion cases every year.[4] The global burden of diarrheal disease and deaths varies in developed and developing countries with half of all diarrheal deaths occurring in the African region.[5]. Children living in poor areas have higher case-fatality rates compared to children living in the developed world due to poor access to safe water, sanitation, hygiene, urgent medical care and effective hygiene and sanitation measures. [6-8] The prevalence and correlates for diarrhea vary with geographical area, and between countries.[9] Diarrheal diseases are associated with socioeconomic status, especially with mother's educational status. Poor environmental sanitation and hygiene, inadequate water supplies and poverty.[10]

The 2012 Declaration on scaling up treatment of diarrhea and pneumonia from donors, industry and non- governmental organizations (NGOs) called on all high burden countries and the international community to provide the resources, political will and focused action needed for ending preventable childhood pneumonia and diarrhea deaths.[11] In line with this declaration, Rwanda has made health sector reforms and reinforced specific programs such as expanded program of immunization, the fight against diseases including diarrhea, the integrated management of childhood illness, and the high impact interventions at the community level.[12]

Moreover, vaccine against rotavirus responsible for diarrhea has been introduced in Rwanda routine immunization program in 2012. Nevertheless the Rwandan Ministry of Health still lists diarrhea as the third (after malaria and pneumonia) among top ten causes of under five children morbidity with prevalence of 20 percent in 2014 in all health centers nationwide.[1] There is a paucity of information about the determinants of diarrhea in under-five years old children in Rwanda. This study intended to do a deep analysis of the RDHS data and find the determinants of childhood diarrhea, in Rwanda. 


\section{Methods}

A cross-sectional study design with a deep analysis of the dataset from the Rwanda Demographic and Health Survey 2014-2015 was used. The 2014-2015 Survey was the fifth standard national survey, implemented by the National Institute of Statistics of Rwanda (NISR) in a period of six months from November 2014 to April 2015. The main objective of the 2014-15 RDHS was to obtain information on demographic and health indicators, including family planning; maternal mortality; infant and child mortality; nutrition status of mothers and children; antenatal care, delivery, and postnatal care; childhood diseases; and pediatric immunization. In addition, the survey measured indicators such as domestic violence, the prevalence of anemia and malaria among women and children, and the prevalence of HIV infection in Rwanda. A total of 12,793 households were selected and 12,699 completed the Household Questionnaire, yielding a response rate of 99.9 percent. In the 12,699 households surveyed, 13,564 women age 15-49 were identified as being eligible for the individual interview; interviews were completed with 13,497 of these women, yielding a response rate of 99.5 percent.[14]

In this study, we included a population of 2,841 children under five years old from the individual record file (IR). Bivariate analysis with Chi-square test was performed to assess the association factors Multivariate analysis was performed with logistic regression model to assess the relative effect of the risk factors on diarrhea.

Descriptive statistics were used to summarize the data. We used Chi-square test to evaluate the association between sociodemographic factors and child diarrhea. A significance level of 0.05 at $95 \%$ confidence interval was considered. The data was analyzed using Stata 13.

Logistic regression analysis was used to assess the determinants of under-fivechilddiarrhea. Forvariables that showed association $(\mathrm{P} \leq 0.05)$ in bivariate analysis, useful variables that define diarrhea were subsequently identified Ethical considerations

This study used a secondary data analysis of the RDHS 2014-2015.The Survey has been approved by the Rwanda National Ethics Committee (RNEC). The researchers have been authorized to download and use Survey data from the Archives of Demographic and Health Surveys (DHS) Program.

\section{Results}

\section{Socio-demographic characteristics of respondents}

More than a quarter $734(25.8 \%)$ of all children included in the study were in the age group between 11-23 months and $247(8.7 \%)$ were between 48 and 59 months. The study population had slightly more males than females. $1440(50.7 \%)$ children were males while 1401 (49.3\%) were females. Nearly three quarters $(73.3 \%)$ of children's mothers were between 19 and 34 years. The largest proportion of children's mothers $72.1 \%$ (2049) had attained their primary education while $14.1 \%$ (402) had no formal education. A large proportion $(83.3 \%)$ of participants resided in the rural area while $16.7 \%$ were in urban area. Socioeconomic status was classified into 5 categories where poorest and poor were $24 \%$ and $22 \%$ respectively (Table1).

Table1. Household socio-demographic characteristics of respondents

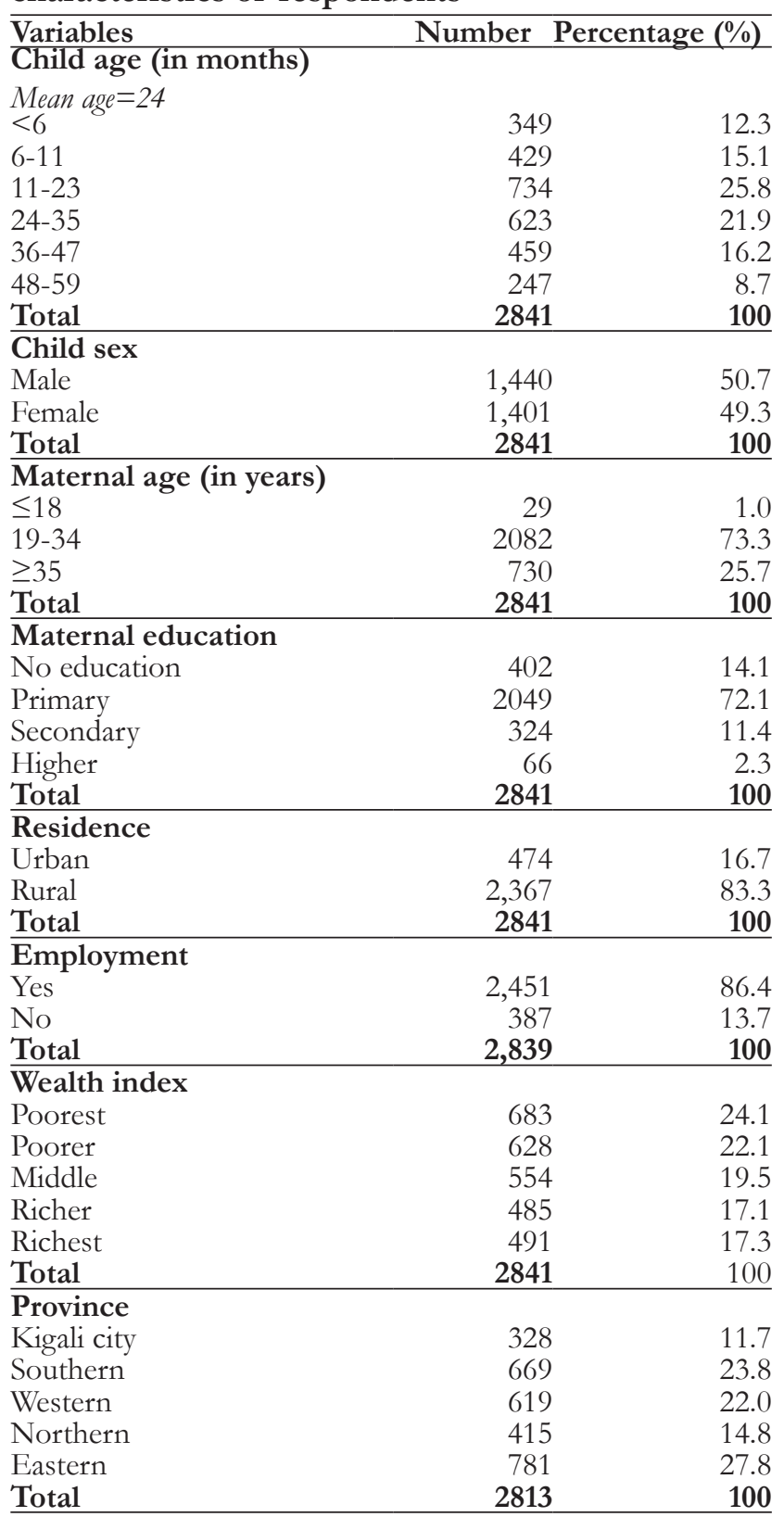

\section{Environmental characteristics of the households}

Households using improved sources of water were 1940 $(70.1 \%)$ as compared to $(29.9 \%)$ who used non improved sources of water. The households with improved toilet facility represent $71 \%$. Around two thirds $(60.4 \%)$ of the households used above 15 minutes for a round trip to obtain water for domestic use, and $782(27 \%)$ use to spend around 15 minutes or less. The majority (77.9\%) of households were built with non-improved floor material like earth or sand (Table 2). 
Table 2. Environmental characteristics of the households

\begin{tabular}{lrr}
\hline Variables & Frequency & Percentage \\
\hline Source of water & & \\
Improved & 1940 & 70.1 \\
Non improved & 827 & 29.9 \\
Total & $\mathbf{2 7 6 6}$ & $\mathbf{1 0 0}$ \\
\hline Toilet availability & & \\
Available & 2,120 & 78.2 \\
Not available & 593 & 21.9 \\
Total & $\mathbf{2 7 1 3}$ & $\mathbf{1 0 0}$ \\
Types of toilet facility & & \\
Improved & 1767 & 71.0 \\
Non improved & 721 & 29.0 \\
Total & $\mathbf{2 4 8 8}$ & $\mathbf{1 0 0}$ \\
\hline Main floor material & & \\
Improved & 621 & 22.1 \\
Non improved & 2188 & 77.9 \\
Total & $\mathbf{2 8 0 9}$ & $\mathbf{1 0 0}$ \\
\hline
\end{tabular}

Bivariate analysis for associations with child diarrhea

Chi-square test was performed and variables including wealth index, child age and maternal education showed a statistically significant association with under five child diarrhea (P-value $<0.001)$. Household floor material also showed some association with diarrhea $(\mathrm{P}$-value $<0.05)$.

Table 3. Association of sociodemographic, and environmental factors with child diarrhea

\begin{tabular}{|c|c|c|c|c|}
\hline \multirow{3}{*}{ Variables } & \multicolumn{2}{|c|}{ Had diarrhea } & \multirow[b]{2}{*}{ Total } & \multirow{3}{*}{ P-value } \\
\hline & Yes & No & & \\
\hline & n $(\%)$ & n $\quad(\%)$ & n $\quad(\%)$ & \\
\hline \multicolumn{5}{|l|}{ Child age (in months) } \\
\hline$<6$ & $23(0.8)$ & $325(11.5)$ & $349(12.3)$ & \multirow{6}{*}{$.001 * * *$} \\
\hline $7-11$ & $76(2.7)$ & $353(12.4)$ & $429(15.1)$ & \\
\hline $12-23$ & $181(6.4)$ & $553(19.5)$ & $734(25.8)$ & \\
\hline $24-35$ & $85(3.0)$ & $538(19.0)$ & $623(21.9)$ & \\
\hline $36-47$ & $29(1.0)$ & $430(15.1)$ & $459(16.2)$ & \\
\hline $48-59$ & $9(0.3)$ & $239(8.4)$ & $247(8.7)$ & \\
\hline \multicolumn{5}{|c|}{ Maternal age (in years) } \\
\hline$\leq 18$ & $5(0.2)$ & $24(0.8)$ & $29(1.0)$ & \multirow{3}{*}{.673} \\
\hline $19-34$ & $300(10.6)$ & $1781(62.7)$ & $2082(73.3)$ & \\
\hline$\geq 35$ & $97(3.4)$ & $633(22.3)$ & $730(25.7)$ & \\
\hline \multicolumn{5}{|l|}{ Child sex } \\
\hline Male & $216(7.6)$ & $1224(43.1)$ & $1440(50.7)$ & \multirow[t]{2}{*}{.238} \\
\hline Female & $187(6.6)$ & $1214(42.7)$ & $1401(49.3)$ & \\
\hline \multicolumn{5}{|l|}{ Family size } \\
\hline$<5$ & $165(5.8)$ & $1057(37.2)$ & $1221(43.0)$ & \multirow{4}{*}{.815} \\
\hline 5 to 7 & $189(6.7)$ & 1109 (39.1) & $1299(45.7)$ & \\
\hline 8 to 10 & $45(1.6)$ & $256(9.0)$ & $301(10.6)$ & \\
\hline$\geq 11$ & $3(0.1)$ & $16(0.6)$ & $20(0.7)$ & \\
\hline \multicolumn{5}{|l|}{ Wealth index } \\
\hline Poorest & $123(4.3)$ & $560(19.7)$ & $683(24.0)$ & \multirow{5}{*}{$.001 * * *$} \\
\hline Poorer & $99(3.5)$ & $529(18.6)$ & $628(22.1)$ & \\
\hline Middle & $72(2.5)$ & $482(17.0)$ & $554(19.5)$ & \\
\hline Richer & $63(2.2)$ & $423(14.9)$ & $485(17.1)$ & \\
\hline Richest & $46(1.6)$ & $445(15.7)$ & $491(17.3)$ & \\
\hline \multicolumn{5}{|l|}{ Residence } \\
\hline Urban & $60(2.1)$ & 414 (14.6) & $474(16.7)$ & \multirow{2}{*}{.369} \\
\hline Rural & $343(12.1)$ & $2025(71.3)$ & $2367(83.3)$ & \\
\hline \multicolumn{5}{|l|}{ Maternal education } \\
\hline No formal education & $74(2.6)$ & $324(11.5)$ & $398(14.2)$ & \multirow{3}{*}{$.001 * * *$} \\
\hline Primary & $289(10.2)$ & $1740(61.8)$ & $2049(72.1)$ & \\
\hline Secondary and higher & $35(1.2)$ & $351(12.5)$ & $66(13.7)$ & \\
\hline \multicolumn{5}{|c|}{ Household floor materials } \\
\hline Non improved & $330(11.7)$ & $1858(66.2)$ & $2188(77.9)$ & \multirow[t]{2}{*}{$.014 * *$} \\
\hline Improved & $65(2.3)$ & $556(19.8)$ & $621(22.1)$ & \\
\hline \multicolumn{5}{|l|}{ Shared toilet } \\
\hline No & $280(10.3)$ & $1840(67.8)$ & $2120(78.1)$ & \multirow[t]{2}{*}{.229} \\
\hline Yes & $90(3.3)$ & 503 (18.6) & $593(21.9)$ & \\
\hline
\end{tabular}


Logistic regressions to assess the risks for under five child diarrhea

In the final logistic regression model, age and wealth index showed a consistency of association with diarrhea. Children in the age groups of 12-23, 24-35, 6-11months were more likely to experience diarrhea than children aged 48-59 months, OR: 7.6, CI [4.7-12.2], P-value: 0.001; OR: 3.8 [2.3-6.2], P-value: 0.001; OR: 5.0 [3.18.2], P-value:0.001 respectively. Children from poorest and poorer families were also more at risk of diarrhea than children from richest families. OR: 2, CI [1.3-2.9], P-value: 0.001.

Table 4. Multivariate analysis output

\begin{tabular}{lllll}
\hline Variables & Full model & & Reduced model & \\
\hline Child age (in months) & OR [95\% CI] & $\mathbf{p}$ & OR [ 95\% CI] & p \\
\cline { 2 - 4 } $48-59$ & 1.0 & & 1.0 & 0.109 \\
$0-6$ & $1.6[0.8-3.0]$ & 0.147 & $1.7[0.9-3.1]$ & $0.000^{* * *}$ \\
$6-11$ & $5.1[3.1-8.3]$ & $0.000^{* * *}$ & $5.0[3.1-8.2]$ & $0.000^{* * *}$ \\
$12-23$ & $7.6[4.7-12.3]$ & $0.000^{* * *}$ & $7.6[4.7-12.2]$ & $0.000^{* * *}$ \\
$24-35$ & $3.8[2.3-6.2]$ & $0.000^{* * *}$ & $3.8[2.3-6.2]$ & 0.029 \\
$36-47$ & $1.8[1.1-3.0]$ & $0.029^{* *}$ & $1.8[1.1-3.0]$ & \\
Wealth index & & & & $0.001^{* * *}$ \\
Richest & 1.0 & & 1.0 & $0.001^{* * *}$ \\
Poorest & $1.8[1.1-3.2]$ & $0.029^{* *}$ & $2.0[1.3-2.9]$ & 0.133 \\
Poorer & $1.8[1.0-3.1]$ & $0.046^{* *}$ & $2.0[1.3-3.0]$ & \\
Middle & $1.3[0.8-2.4]$ & 0.316 & $1.4[0.9-2.2]$ & \\
Richer & $1.3[0.8-2.0]$ & 0.350 & $1.3[0.9-2.1]$ & \\
Maternal education & & & & \\
Tertiary & 1.0 & & & \\
No education & $1.6[1.0-2.6]$ & 0.064 & & \\
Primary & $1.4[0.9-2.1]$ & 0.161 & & \\
Household floor material & & & \\
Improved & 1.0 & 0.769 & \\
Non-improved & $0.9[0.6-1.5]$ & & & \\
\hline
\end{tabular}

\section{Discussion}

In this study, we used multivariate logistic regression analysis to assess the effect of variables including child age, wealth index, maternal education, and household floor material on childhood diarrhea. The findings revealed that child age is significantly associated with diarrhea (P-value $<0.001)$. The risk of diarrhea increases with child age where 12-23 months were the pick age with a higher likelihood for diarrhea that than the age range of 48-59 months. Moreover, the risk was fivefold among children in the age range between six to eleven months. These findings are supported by some studies which concluded that children aged between six months to two years have high risk for diarrhea. The risk reduces as the child grows older.[15-17]. Younger child age exposure to diarrhea has been linked to underdeveloped immune system that is incapable of mounting an effective immunological response to the diseases. As the child grows older, the development of the immunity after repeated exposure reduces susceptibility to the diseases [18]. In addition, young children tend to ingest material while crawling. These materials may be contaminated and cause diarrhea illness.
This study also concluded that low socioeconomic status as indicated with the wealth index is associated with diarrhea. These findings are consistent with other studies from low-income countries, where children from poor families were at higher risk of diarrhea. Poorest and poorer families are less likely to have the financial resources to buy healthy or enough food.[19,20] The evidence generated from a systematic review of literature also revealed that young age of the child (usually $<24$ months), and low socioeconomic status are the risk factors of acute childhood diarrhea.[17]

\section{Conclusion}

Diarrhea is one of the top ten causes of child illness among under five years old children in Rwanda. This study therefore identified important determinants of under five children diarrhea and concludes that low socioeconomic status, and younger child age category are the potential determinants of under-five diarrhea. 


\section{Recommendations}

Based on the study findings, efforts to strengthen families with under-five children should be undertaken to increase their social economic status and to ensure appropriate nutrition of their children.

\section{Limitations of the study}

The study focused on a population of children aged between 0-59 months. This population is believed to be at the highest risk of diarrhea. The study was limited by some factors related the nature of RDHS datasets. The role of hand washing in prevention of diarrhea has been highlighted in the literature. However, the RDHS did not collect data on hand washing practice.

\section{Conflict of interest}

The authors declare that there is no conflict of interest.

This article is published open access under the Creative Commons Attribution-NonCommercialNoDerivatives (CC BY-NC-ND4.0). People can copy and redistribute the article only for noncommercial purposes and as long as they give appropriate credit to the authors. They cannot distribute any modified material obtained by remixing, transforming or building upon this article. See https://creativecommons.org/ licenses/by-nc-nd/4.0/

\section{References}

1. WHO | Diarrhoeal disease. WHO. World Health Organization; 2017;

2. Thiam S, Diène AN, Fuhrimann S, Winkler MS, Sy I, Ndione JA, et al. Prevalence of diarrhoea and risk factors among children under five years old in Mbour, Senegal: a cross-sectional study. Infect Dis Poverty. BioMed Central; 2017;6:109.

3. Carvajal-Vélez L, Amouzou A, Perin J, Maïga A, Tarekegn H, Akinyemi A, et al. Diarrhea management in children under five in sub-Saharan Africa: does the source of care matter? A Countdown analysis. BMC Public Health. BioMed Central; 2016;16:830.

4. WHO. Diarrhoeal disease fact sheet. World Health Organization; 2017;

5. Liu L, Johnson HL, Cousens S, Perin J, Scott S, Lawn JE, et al. Global, regional, and national causes of child mortality: an updated systematic analysis for 2010 with time trends since 2000. Lancet. Elsevier; 2012;379:2151-61.

6. Bezatu Mengistie1 YB, Alemayehu Worku. Prevalence of diarrhea and associated risk factors among children under-five years of age in Eastern Ethiopia: A crosssectional study. Open J Prev Med. 2013;

7. Prüss-Ustün A, Bartram J, Clasen T, Colford JM, Cumming O, Curtis V, et al. Burden of disease from inadequate water, sanitation and hygiene in lowand middle-income settings: a retrospective analysis of data from 145 countries. Trop Med Int Health. Wiley-Blackwell; 2014;19:894-905.
8. Aristide R. Bado ASS\& EIN. Trends and risk factors for childhood diarrhea in sub-Saharan countries (1990-2013): assessing the neighborhood inequalities. Glob Health Action. 2016;

9. Siziya S, Muula AS, Rudatsikira E. Correlates of diarrhoea among children below the age of 5 years in Sudan. Afr Health Sci. Makerere University Medical School; 2013;13:376-83.

10. Bethesda J. O Connell, Megan A. Quinn PS. Risk factors of diarrheal disease among children in the East African countries of Burundi, Rwanda and Tanzania. Glob J Med Public Heal. 2017;6.

11. UNICEF \& WHO. The Integrated Global Action Plan for the Prevention and Control of Pneumonia and Diarrhoea (GAPPD) The integrated Global Action Plan for Pneumonia and Diarrhoea (GAPPD) WHO Library Cataloguing-in-Publication Data End preventable deaths: Global Action Pla. 2013.

12. MoH. Ministry of Health Annual Report 2011 2012. Minist. Heal. Annu. Rep. 2011.

13. MoH. Weekly Epidemiology Bulletin. 2013.

14. Ministry of Health (MOH). National Institute of Statistic of Rwanda (NISR) [Rwanda]. 2016.

15. Fischer Walker CL, Perin J, Aryee MJ, Boschi-Pinto C, Black RE. Diarrhea incidence in low- and middleincome countries in 1990 and 2010: a systematic review. BMC Public Health. BioMed Central; 2012;12:220.

16. Mengistie B, Berhane Y, Worku A. Prevalence of diarrhea and associated risk factors among children under-five years of age in Eastern Ethiopia: A cross-sectional study. Open J Prev Med. Scientific Research Publishing; 2013;03:446-53.

17. Ganguly E, Sharma PK, Bunker CH. Prevalence and risk factors of diarrhea morbidity among under-five children in India: A systematic review and meta-analysis. Indian J Child Health. NIH Public Access; 2015;2:152-60.

18. Shah M, Kathiiko C, Wada A, Odoyo E, Bundi M, Miringu G, et al. Prevalence, seasonal variation, and antibiotic resistance pattern of enteric bacterial pathogens among hospitalized diarrheic children in suburban regions of central Kenya. Trop Med Health. BioMed Central; 2016;44:39.

19. Chowdhury MRK, Khan M, Rafiqul Islam M, Perera NKP, Shumack MK, Kader M. Low maternal education and socio-economic status were associated with household food insecurity in children under five with diarrhoea in Bangladesh. Acta Paediatr. 2016;105:555-61.

20. Women's Health and Action Research Centre (Nigeria) AT, Oluwasanu MM, John-Akinola YO, Oladunni O, Adebowale SA. African journal of reproductive health. Afr. J. Reprod. Health. Women's Health and Action Research Centre; 1997. 